\title{
Fibroblast growth factor receptors in breast cancer: expression, downstream effects, and possible drug targets
}

\author{
M Tenhagen ${ }^{1}, P J$ van Diest ${ }^{1}$, I A Ivanova ${ }^{1}, E$ van der Wall ${ }^{2}$ and \\ $P$ van der Groep ${ }^{1,2}$
}

${ }^{1}$ Department of Pathology and ${ }^{2}$ Division of Internal Medicine and Dermatology, University Medical Center Utrecht, PO Box 85500 , 3508 GA Utrecht, The Netherlands

(Correspondence should be addressed to P van der Groep; Email: p.vandergroep@umcutrecht.nl)

\begin{abstract}
Cancer treatments are increasingly focusing on the molecular mechanisms underlying the oncogenic processes present in tumors of individual patients. Fibroblast growth factor receptors (FGFRs) are among the many molecules that are involved in oncogenesis and are currently under investigation for their potential as drug targets in breast cancer patients. These receptor tyrosine kinases play a role in several processes including proliferation, angiogenesis, and migration. Alterations in these basal processes can contribute to the development and progression of tumors. Among breast cancer patients, several subgroups have been shown to harbor genetic aberrations in FGFRs, including amplifications of FGFR1, FGFR2, and FGFR4 and mutations in FGFR2 and FGFR4. Here, we review in vitro and in vivo models that have partly elucidated the molecular implications of these different genetic aberrations, the resulting tumor characteristics, and the potential of FGFRs as therapeutic targets for breast cancer treatment.
\end{abstract}

Endocrine-Related Cancer (2012) 19 R115-R129

\section{Introduction}

Breast cancer is the most commonly occurring cancer in women with 1.4 million new cases diagnosed worldwide annually (Jemal et al. 2010). Currently, breast surgery and irradiation are the local therapies of choice, and chemohormonal and antihuman epidermal growth factor receptor 2 (HER2 (ERBB2)) therapies are commonly used as a systemic treatment to prevent outgrowth of distant metastases (Prosnitz et al. 2001). Progress in local and systemic treatment has clearly improved the prognosis of breast cancer patients, but still 458503 women died from the disease in 2008 (Ferlay et al. 2008).

Therefore, the development of new therapies is focused on the specific genetic abnormalities in individual cancers, resulting in more personalized treatment (Bild et al. 2006, Alvarez et al. 2010). In order to develop these personalized therapies, it is important to fully understand the molecular basis of the oncogenic pathways that can be targeted in breast cancer.

Receptor tyrosine kinases (RTKs) regulate cell proliferation, differentiation, and apoptosis: processes that are often deregulated in cancer. Several RTKs, including epidermal growth factor receptor (EGFR), HER2, and platelet-derived growth factor receptor (PDGFR (PDGFRB)), have been extensively studied leading to the development of targeted inhibitors, such as trastuzumab and imatinib, that have been successfully used to treat cancer patients overexpressing HER2 and PDGFR respectively (Arteaga 2003, Mukai 2010, Peterson 2011).

This review focuses on the fibroblast growth factor receptor (FGFR) family of RTKs. FGFR signaling cascades, the genetic aberrations in FGFRs, and their correlations with other genotypic and phenotypic features found in breast cancer will be summarized. Finally, therapies currently under development as well as new possibilities to target the FGFR pathway will be discussed. Articles were retrieved through PubMed using the search items 'breast' or 'mammary' and 'FGFR'. In addition, the references of the retrieved papers were screened for additional papers. Only papers in English were further considered. 


\section{FGFRs: expression and signaling}

The FGFR family comprises four members, FGFRl, $-2,-3$, and -4 (Turner \& Grose 2010), located on chromosomes 8p12, 10q26, 4p16.3, and 5q35.1-qter respectively. All FGFRs contain an extracellular ligand-binding domain, a transmembrane domain, and an intracellular tyrosine kinase (TK) domain (Eswarakumar et al. 2005). The extracellular domain has three immunoglobulin (Ig)-like domains (IgI-III, Fig. 1). The second and third Ig domains are responsible for binding the FGF ligand (Beenken \& Mohammadi 2009). The FGF family of secreted glycoproteins consists of 18 members. The different FGFs and their corresponding receptors are expressed in a tissue-specific way. This tissue-specific expression pattern and the differences in binding affinity contribute to the specificity of the ligand-receptor interaction (Eswarakumar et al. 2005, Turner \& Grose 2010). Furthermore, this specificity is also regulated by splicing. FGFR1, -2, and -3 have two splice variants of the IgIII domain, resulting in IIIb and IIIc isoforms. The IIIb isoform is present on the epithelial cells and IIIc is expressed by mesenchymal cells (Beenken \& Mohammadi 2009).

FGFs are released from the extracellular matrix (ECM) by heparins, proteases, or specific FGF-binding proteins. FGFs bind FGFRs and form a stable structure together with heparin sulfate proteoglycans on the cell surface (Harmer et al. 2004, Mohammadi et al. 2005, Turner \& Grose 2010). Klotho family proteins also facilitate the FGF-FGFR interaction (Wu et al. 1991, Kurosu et al. 2006) by binding to FGFRs and increasing the affinity of FGF for its receptor, thus

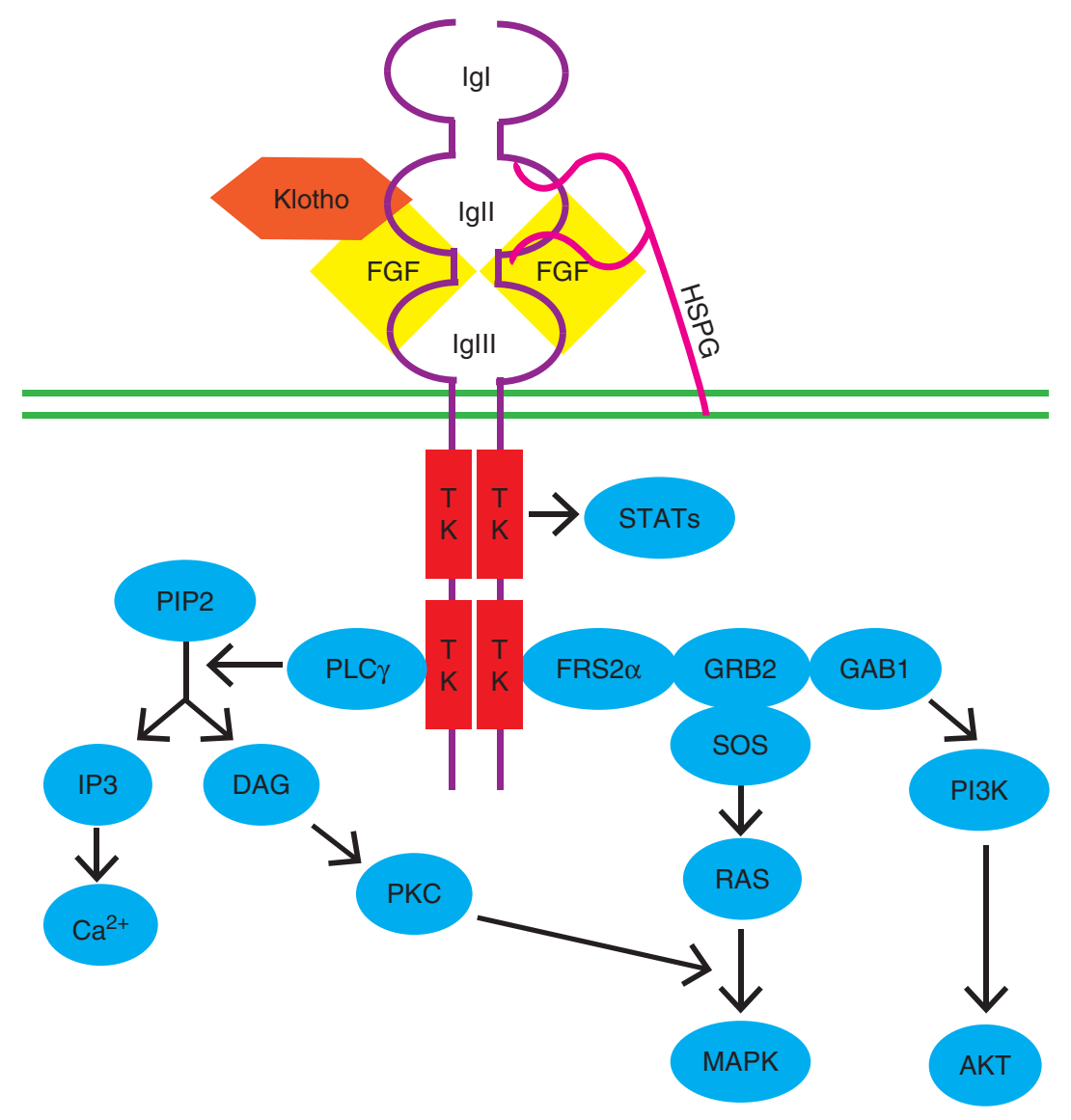

Figure 1 FGF-FGFR structure and downstream signaling. The extracellular domain of FGFRs consists of three ligand-binding Ig domains. Binding of the ligand is stabilized by HSPG and Klotho. Intracellular tyrosine kinase domains (TK) are present. Upon ligand binding, the receptors dimerize, resulting in cross-phosphorylation of the tyrosine kinase domains. This leads to binding of several docking proteins, which can also be phosphorylated. Downstream signaling occurs through four main pathways: PLC $\gamma$, STATs, AKT, and MAPK. FGF, fibroblast growth factor; HSPG, heparin sulfate proteoglycans; TK, tyrosine kinase domain; STAT, signal transducer and activator of transcription; FRS2 $\alpha$, fibroblast growth factor receptor substrate $2 \alpha$; GRB2, growth factor receptor-bound protein 2; GAB1, GRB2-associated binding protein 1; PI3K, phosphoinositide-3 kinase; AKT, v-akt murine thymoma viral oncogene;

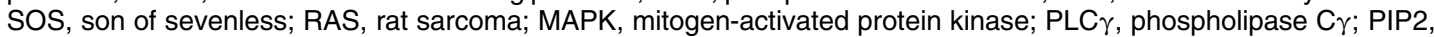
phosphatidylinositol 4,5-biphosphate; IP3, inositol 1,4,5-triphosphate; DAG, diacylglycerol; PKC, protein kinase C. 
resulting in increased receptor activation (Kurosu et al. 2006). Each FGFR isoform can bind multiple FGF ligands and some ligands are common to several receptors (Eswarakumar et al. 2005).

Ligand binding results in FGFR dimerization and subsequent activation of the intracellular kinase domain, leading to cross-phosphorylation of tyrosine residues present on the intracellular tail of the receptor (Turner \& Grose 2010). Several docking proteins are able to bind to these phosphorylated residues, resulting in their phosphorylation and subsequent activation. Major pathways downstream of activated FGFRs include the rat sarcoma mitogen-activated protein kinase (RAS-MAPK) pathway and the phosphoinositide-3 kinase v-akt murine thymoma viral oncogene (PI3K (PIK3CA)-AKT (AKT1)) pathway whose activation is mediated via FGFR substrate $2 \alpha$ (FRS2 $\alpha$ (FRS2)) and several other adaptor molecules. Furthermore, protein kinase $\mathrm{C}$ is activated via phospholipase $\mathrm{C} \gamma(\mathrm{PLC} \gamma(\mathrm{PLCG}))$, and finally activation of signal transducer and activator of transcription (STAT) signaling can take place (Acevedo et al. 2009, Turner \& Grose 2010; Fig. 1).

All these pathways play an important role in cell proliferation, differentiation, inhibition of apoptosis, and migration. In addition, FGFR signaling is involved in angiogenesis and wound repair (Eswarakumar et al. 2005, Turner \& Grose 2010). Downstream effector activation is cell type specific and may be dependent on cross talk with other signaling pathways (Dailey et al. 2005). Although different FGFRs signal via similar pathways, differences in downstream effector activation have been described. Activation of downstream targets by FGFR4 is less strong than FGFR1 (Vainikka et al. 1994), and FGFR1 signaling sustains longer than FGFR2 because of faster degradation of FGFR2 after activation (Xian et al. 2007). Finally, even though FGFR isoforms have some specificity for different FGF ligands (Eswarakumar et al. 2005), no conclusive evidence has been found that specific FGFs activate specific downstream pathways (Dailey et al. 2005).

\section{Aberrations in FGFRs found in breast cancer}

Deregulation of FGFR activity could contribute to cancer development by increasing cell proliferation, angiogenesis, and inhibiting apoptosis. Genetic aberrations in FGFRs have indeed been found to be associated with breast cancer and are described below.

\section{FGFR1}

No germ-line mutations in FGFRl have been identified to date. However, a somatic mutation $(K 566 R)$ was found in a sample from a patient with basal-like, triplenegative breast cancer (Kan et al. 2010). Whether this mutation is present in other breast cancer patients remains to be investigated. Furthermore, a $S 125 L$ mutation was described in a ductal breast carcinoma cell line (HCC1395; Stephens et al. 2005, Greenman et al. 2007). However, whether these mutations have consequences for FGFR1 function and its role is in breast cancer development and/or progression have not been investigated.

Several studies have identified amplifications of FGFRl in breast cancer (Chin et al. 2006, Letessier et al. 2006, Reis-Filho et al. 2006, Elbauomy Elsheikh et al. 2007, Marchio et al. 2008, Andre et al. 2009, Kadota et al. 2009, Moelans et al. 2010; Table 1). The percentage of FGFRl amplifications found using different techniques ranges from 7.5 to $17 \%$. This variability could be caused by differences between tumor samples, which were not selected for histopathological type or clinical parameters. Furthermore, each study used a different technique to assess the copy number alterations, which can also account for the

Table 1 Copy number alterations in FGFR1 identified in breast cancer patients

\begin{tabular}{|c|c|c|c|}
\hline $\begin{array}{l}\text { Breast cancer } \\
\text { cases }(n)\end{array}$ & $\begin{array}{l}\text { Technique, whole } \\
\text { genome/gene specific }\end{array}$ & $\begin{array}{l}\text { Results: FGFR1 } \\
\text { amplification/loss }\end{array}$ & Reference \\
\hline 106 & aCGH: $70 \mathrm{~kb}$ interval, whole genome & Highly amplified in $10 \%$ & Andre et al. (2009) \\
\hline 161 & SNP DNA microarray, whole genome & Amplified in $7.5 \%$ & Kadota et al. (2009) \\
\hline 1319 & FISH, gene specific & Amplified in $9.4 \%$ & Letessier et al. (2006) \\
\hline 496 & $\mathrm{CISH}$, gene specific & Amplified in $8.7 \%$ & Elbauomy Elsheikh et al. (2007) \\
\hline 104 & MLPA, gene specific & $\begin{array}{l}\text { Amplified in } 17 \% \\
\text { (7\%: highly amplified) } \\
\text { Lost in } 10 \%\end{array}$ & Moelans et al. (2010) \\
\hline 24 & $\mathrm{CISH}$, gene specific & Amplified in $16.6 \%$ & Marchio et al. (2008) \\
\hline
\end{tabular}

aCGH, array comparative genome hybridization; $\mathrm{FISH}$, fluorescent in situ hybridization; $\mathrm{CISH}$, chromogenic in situ hybridization; MLPA, multiplex ligation-dependent probe amplification. 
discrepancies in the results. Microarray expression analyses showed that FGFRI amplifications were associated with increased FGFRl RNA expression (Chin et al. 2006, Andre et al. 2009).

Several studies have described that FGFRI amplifications were not associated with some pathological characteristics (Table 2). Associations with proliferation and HER2 status are inconsistent between studies, possibly due to differences in techniques. Proliferation was estimated by assessing the percentage of Ki-67-positive cells (Letessier et al. 2006) or the mitotic activity index (Moelans et al. 2010), and HER2 expression was also evaluated in different ways (Letessier et al. 2006, Elbauomy Elsheikh et al. 2007, Kadota et al. 2009, Moelans et al. 2010). Even though estrogen receptor (ER) and progesterone receptor (PR) statuses were assessed in the same way in the different studies, the correlations with FGFRl amplification were inconsistent. Confounder effects by clinical or pathological parameters could provide an explanation for the differences in association between expression of these hormone receptors and FGFR1 amplification.

In addition to pathological features, association analysis of FGFRI amplification with clinical outcome has also been performed (Table 2). Patients with an FGFR1 amplification were more likely to develop distant metastases (Elbauomy Elsheikh et al. 2007). In addition, a trend for FGFRI amplification and a shorter disease-free survival (DFS) was observed. Finally, amplification of FGFRl was significantly

Table 2 Association of FGFR1 amplification in unselected cohorts with clinical and pathological parameters

\begin{tabular}{|c|c|c|}
\hline Parameter & Association: yes/no & Reference \\
\hline Development of distant metastasis & Yes: positive association & Elbauomy Elsheikh et al. (2007) \\
\hline Grade & No & $\begin{array}{l}\text { Letessier et al. (2006), Elbauomy Elsheikh } \\
\text { et al. (2007), and Moelans et al. (2010) }\end{array}$ \\
\hline Tumor size & No & $\begin{array}{l}\text { Letessier et al. (2006), Elbauomy Elsheikh } \\
\text { et al. (2007), Kadota et al. (2009), and } \\
\text { Moelans et al. (2010) }\end{array}$ \\
\hline Histopathological type & No & $\begin{array}{l}\text { Letessier et al. (2006), Kadota et al. (2009), } \\
\text { and Moelans et al. (2010) }\end{array}$ \\
\hline Lymph node invasion & No & $\begin{array}{l}\text { Letessier et al. (2006), Elbauomy Elsheikh } \\
\text { et al. (2007), and Kadota et al. (2009) }\end{array}$ \\
\hline Vascular invasion & No & $\begin{array}{l}\text { Letessier et al. (2006) and Moelans et al. } \\
\text { (2010) }\end{array}$ \\
\hline Tumor stage & No & $\begin{array}{l}\text { Elbauomy Elsheikh et al. (2007) and } \\
\text { Kadota et al. (2009) }\end{array}$ \\
\hline $\begin{array}{l}\text { Molecular subtypes (basal-like, luminal } \\
\text { A/B, ERBB2-positive, normal-like) }\end{array}$ & No & $\begin{array}{l}\text { Letessier et al. (2006) and Moelans et al. } \\
\text { (2010) }\end{array}$ \\
\hline P53 status & No & Letessier et al. (2006) \\
\hline EGFR status & No & Elbauomy Elsheikh et al. (2007) \\
\hline $\begin{array}{l}\text { Expression of low- and high-molecular } \\
\text { weight cytokeratins }\end{array}$ & No & Elbauomy Elsheikh et al. (2007) \\
\hline Androgen receptor status & No & Elbauomy Elsheikh et al. (2007) \\
\hline \multirow[t]{2}{*}{ Proliferation } & No & Moelans et al. (2010) \\
\hline & Yes: positive association & Letessier et al. (2006) \\
\hline \multirow[t]{2}{*}{ ER status: positive or negative } & No & $\begin{array}{l}\text { Letessier et al. (2006), Elbauomy Elsheikh } \\
\text { et al. (2007), and Kadota et al. (2009) }\end{array}$ \\
\hline & Yes: associated with a positive status & Moelans et al. (2010) \\
\hline \multirow[t]{2}{*}{ PR status: positive or negative } & No & $\begin{array}{l}\text { Letessier et al. (2006), Kadota et al. (2009), } \\
\text { and Moelans et al. (2010) }\end{array}$ \\
\hline & Yes: trend with a negative status & Elbauomy Elsheikh et al. (2007) \\
\hline \multirow[t]{2}{*}{ Age $(<50 / \geq 50)$} & No & $\begin{array}{l}\text { Letessier et al. (2006) and Moelans et al. } \\
\text { (2010) }\end{array}$ \\
\hline & $\begin{array}{l}\text { Yes: if amplified, more likely to be } \\
\text { older than } 50\end{array}$ & Elbauomy Elsheikh et al. (2007) \\
\hline \multirow[t]{3}{*}{ HER2 status } & No & $\begin{array}{l}\text { Letessier et al. (2006) and Moelans et al. } \\
\text { (2010) }\end{array}$ \\
\hline & $\begin{array}{l}\text { Yes: inverse correlation with Her2 } \\
\text { overexpression }\end{array}$ & Elbauomy Elsheikh et al. (2007) \\
\hline & $\begin{array}{l}\text { Yes: amplification was positively } \\
\text { associated with Her2 + status }\end{array}$ & Kadota et al. (2009) \\
\hline
\end{tabular}

EGFR, epidermal growth factor receptor; ER, estrogen receptor; PR, progesterone receptor. 
associated with a shorter overall survival (OS), independent of other prognosticators such as grade, tumor size, lymph node invasion, and ER status. Interestingly, FGFRl amplification remained a significant independent risk factor for poor DFS and OS in ER-positive but not in ER-negative cases (Elbauomy Elsheikh et al. 2007). This suggests that there may be an interaction between FGFR1 and ER signaling resulting in a poor prognosis. The observation that FGFR1 amplification is associated with a poor prognosis in ER-positive breast cancer was confirmed in a group of ER-positive tumor samples from patients treated with adjuvant endocrine therapy (tamoxifen). In this group, FGFRl amplification was significantly associated with decreased metastasis-free survival compared with samples with normal FGFR1 levels (Turner et al. 2010b). Finally, two studies showed an association between amplification of 8p11-12 where FGFRl is located and poor disease outcome. Although these analyses do not specifically show FGFRI amplification in the breast cancer samples, they support the findings in previous studies (Chin et al. 2006, Letessier et al. 2006).

The function of FGFRl as an oncogene has been disputed due to the results of functional studies in cell lines carrying 8p11-12 amplifications, which showed that FGFR inhibition did not affect the proliferation (Ray et al. 2004). Several studies have identified other potential oncogenes located on 8p11-12, including PPAPDC1B, RABIIFIP1, LSM1, BAG4, C8ORF4, and WHSC1L1 (Garcia et al. 2005, Gelsi-Boyer et al. 2005, Yang et al. 2006, Bernard-Pierrot et al. 2008). These results do not exclude the possibility of multiple genes in the 8p11-12 region acting as oncogenes, which might even cooperate.

In addition to its suggested role as an oncogene, there is some evidence that FGFR1 may have a tumor suppressor function in breast cancer. Loss of FGFRl was found in $10 \%$ of invasive breast cancer samples (Moelans et al. 2010). Another study identified a deletion of 8p11-12 in breast carcinomas, which was shown to be associated with a poor outcome (Chin et al. 2006). However, as this region contains many genes, it is not certain whether poor prognosis can be attributed to the specific loss of FGFRI.

\section{FGFR2}

So far, only one somatic mutation $(R 203 C)$ in FGFR2 has been identified in the breast cancer cell line HCC1143 (Stephens et al. 2005, Sjöblom et al. 2006, Greenman et al. 2007). However, several single nucleotide polymorphisms (SNPs) in FGFR2 were found to be highly associated with breast cancer risk and identified $F G F R 2$ as a breast cancer susceptibility gene (Hunter et al. 2007). Four of these SNPs are located in intron 2 of FGFR2. An independent study, using a different panel of SNPs, found an association of another SNP in intron 2 of FGFR2 with breast cancer (Easton et al. 2007). The risk allele of this SNP was significantly associated with a positive ER and PR status and a lower grade (Garcia-Closas et al. 2008). Further analysis of the SNPs located in the second intron of FGFR2 identified a haplotype block of eight SNPs as the minor disease-predisposing allele (Easton et al. 2007, Meyer et al. 2008). This haplotype block is not in linkage disequilibrium with any coding region of $F G F R 2$, excluding a change in protein sequence. Also, when comparing the expression levels of the two most common splicing variations (including or excluding exon 3), no significant difference was observed between the minor and common homozygotes (Meyer et al. 2008). These results indicate that the change in the protein sequence due to the SNPs does not result in a functional difference.

However, when correlating the expression levels of $F G F R 2$ in invasive breast cancer samples with the haplotype of the eight SNPS, mRNA levels of FGFR2 were significantly increased in tumor samples that were homozygous for the minor alleles when compared with samples homozygous for the common alleles (Meyer et al. 2008). This indicates that the risk genotype results in increased expression of FGFR2, which could contribute to the development of breast cancer.

In a genome-wide screen identifying copy number alterations, $F G F R 2$ was found to be amplified in only two $(1.2 \%)$ out of 161 primary breast cancer samples (Kadota et al. 2009). Other genome-wide screens analyzing large groups of unselected breast cancer samples also showed that FGFR2 is rarely amplified (Adelaide et al. 2007), and others did not find any amplifications or losses of FGFR2 (Andre et al. 2009). However, FGFR2 was amplified in $4 \%$ of triplenegative breast cancer samples, whereas no amplification was found in other molecular subtypes. In addition, the mRNA expression levels of FGFR2 were significantly increased in amplified vs nonamplified tumor samples (Turner et al. 2010a), suggesting a potential role for $F G F R 2$ in triple-negative breast cancer. FGFR2 is also suggested to play a role in a subgroup of familial breast cancer patients. When comparing the RNA expression profiles of breast cancer samples of patients with a germ-line mutation in breast cancer 1 and 2 (BRCAl and -2), FGFR2 
expression was significantly higher in breast cancers of BRCA2 mutation carriers (Bane et al. 2009). Finally, increased FGFR2 protein levels in samples from invasive ductal carcinoma (IDC) patients were found to be associated with lower (disease-free) survival rates (Sun et al. 2011). How FGFR2 is regulated in these and BRCA2-mutated patients and whether it is involved in the development or progression of breast cancer are not clear.

\section{FGFR3}

Even though activating mutations in FGFR3 have been identified in several cancer types (Cappellen et al. 1999, Sibley et al. 2001, Zhang et al. 2005, Hafner et al. 2006), no FGFR3 mutations have been found in breast cancer (Sibley et al. 2001,Koziczak et al. 2004, Greenman et al. 2007). FGFR3 mutations cause Saethre-Chotzen syndrome, consisting of premature fusion of one or more skull sutures often accompanied by facial asymmetry and fusion of digits (Sahlin et al. 2009). There is one documented case of a SaethreChotzen patient with a heterozygous missense mutation in exon 7 of FGFR3 (P250R) who also developed breast cancer. This mutation is located in the ligand-binding domain of $F G F R 3$, which leads to activation of the kinase domain (Sahlin et al. 2009). Moreover, this mutation is located near mutational hot spots found in the bladder and cervical carcinomas (R248C and S249C; Sibley et al. 2001). It is unclear whether the mutation found to cause Saethre-Chotzen syndrome also increases the risk of developing breast cancer; therefore, more studies are required to further elucidate this.

A possible role for FGFR3 in therapy resistance was identified in a group of 429 ER-positive breast cancer patients who received tamoxifen as primary therapy. FGFR3 protein levels were significantly increased in patients who did not respond to the treatment (Tomlinson et al. 2012).

\section{FGFR4}

A Gly388Arg $\left(\mathrm{Arg}^{388}\right)$ missense mutation, now known as SNP rs351855, was identified in the transmembrane domain of FGFR4 (Bange et al. 2002). Immunohistochemical analysis of breast cancer samples did not show any correlation of the $A r{ }^{388}$ SNP genotype with FGFR4 expression levels (Thussbas et al. 2006). Sequence analysis of breast cancer samples revealed that the $\mathrm{Arg}^{388}$ genotype, either heterozygous or homozygous, was present in $37-43 \%$ and $8-11 \%$ respectively (Table 3; Bange et al. 2002, Jezequel et al. 2004, Thussbas et al. 2006, Marme et al. 2010). No significant difference could be identified when comparing the distribution of the $\mathrm{Arg}^{388}$ allele in healthy controls and breast cancer patients. This indicates that this SNP is not associated with the initiation of breast cancer (Bange et al. 2002).

$\mathrm{Arg}^{388}$ did not correlate with age, HER2, ER and PR status, and grade (Bange et al. 2002, Jezequel et al. 2004, Thussbas et al. 2006, Marme et al. 2010). Correlations were found for tumor stage (Thussbas et al. 2006, Marme et al. 2010), tumor size (Thussbas et al. 2006), and axillary lymph node involvement (Bange et al. 2002, Jezequel et al. 2004, Thussbas et al. 2006, Marme et al. 2010), but not all of these associations were confirmed by other studies (Bange et al. 2002, Jezequel et al. 2004, Thussbas et al. 2006). Finally, when analyzing the DFS period, no correlation was found with the $\mathrm{Arg}^{388}$ allele (Bange et al. 2002). However, in primary lymph node-positive patients $(\mathrm{N}+)$, DFS was significantly shorter in $\mathrm{Arg}^{388}$ than Gly ${ }^{388}$ carriers (Bange et al. 2002, Thussbas et al. 2006). This suggests that $\operatorname{Arg}^{388}$ could be a marker for increased tumor aggressiveness in advanced breast cancer. However, another study did not find a significant association of $\mathrm{Arg}^{388}$ with DFS in unselected $\mathrm{N}+$ breast cancer cases (Jezequel et al. 2004). $\operatorname{Arg}^{388}$ was not associated with DFS in patients who did not receive adjuvant systemic therapy.

Table 3 FGFR4 Arg $^{388}$ allele distribution in breast cancer patients and healthy controls and associations with clinical or pathological parameters

\begin{tabular}{|c|c|c|c|c|c|}
\hline Cases $(n)$ & $\begin{array}{l}\text { Gly/Gly } \\
\text { (\%) }\end{array}$ & $\begin{array}{l}\text { Gly/Arg } \\
(\%)\end{array}$ & $\begin{array}{c}\operatorname{Arg} / \operatorname{Arg} \\
(\%)\end{array}$ & $\begin{array}{l}\text { Correlations } \\
\text { with Arg allele }\end{array}$ & Reference \\
\hline $\begin{array}{l}\text { Healthy controls } \\
\qquad(n=123)\end{array}$ & 45 & 49 & 6 & & Bange et al. (2002) \\
\hline 145 & 46 & 43 & 11 & Axillary lymph node involvement & Bange et al. (2002) \\
\hline 234 & 52 & 37 & 11 & Axillary lymph node involvement & Jezequel et al. (2004) \\
\hline 372 & 49 & 43 & 8 & $\begin{array}{l}\text { Tumor stage, tumor size, axillary } \\
\text { lymph node involvement }\end{array}$ & Thussbas et al. (2006) \\
\hline 352 & 46 & 43 & 11 & $\begin{array}{l}\text { Tumor stage, axillary lymph node } \\
\text { involvement }\end{array}$ & Marme et al. (2010) \\
\hline
\end{tabular}


When adjuvant systemic therapy was used, DFS and OS were shorter in patients carrying one or two $\mathrm{Arg}^{388}$ alleles, making it a possible marker for therapy resistance in this patient group (Thussbas et al. 2006).

Interestingly, in patients who received neoadjuvant chemotherapy, the $\mathrm{Arg}^{388}$ allele was significantly and independently associated with a better clinical and pathological response (Marme et al. 2010).

In addition to the $\mathrm{Arg}^{388}$ germ-line mutation, a somatic mutation (V510M) in FGFR4 was identified in a tumor sample from a lobular carcinoma patient (Stephens et al. 2005, Greenman et al. 2007). This mutation has not been found in other (breast) cancer patients to date, making its significance unclear.

Amplification of FGFR4 has been reported in breast cancer samples. In a small study, $10 \%$ of breast tumors had FGFR4 amplifications, which were associated with ER and PR positivity and lymph node metastases (Jaakkola et al. 1993). Furthermore, FGFR4 mRNA levels were elevated in $32 \%$ of breast cancer samples (Penault-Llorca et al. 1995). In a retrospective study analyzing ER-positive breast cancers from patients treated with neoadjuvant tamoxifen, high levels of FGFR4 were independently associated with tumor response and survival after treatment (Meijer et al. 2008).

\section{Molecular implications of genetic aberra- tions in FGFRs on tumor characteristics}

As described earlier, genetic aberrations in FGFRs have been shown to contribute to breast cancer risk, tumor progression, and response to therapy. These different outcomes can be due to the fact that FGFRs signal through downstream signaling pathways whose activation depends on several factors. The in vitro and in vivo studies described below give more insight into the functional effects of abnormal FGFR signaling.

\section{FGFR1}

Inducible activation of $F g f r l(\mathrm{i} F g f r l)$ in transgenic mice resulted in increased cell proliferation in the lateral buds and ductal branching of the mammary epithelium (Welm et al. 2002). Furthermore, there was recruitment of macrophages, which are required for lateral bud formation and also play a role in the formation of small blood vessels (Schwertfeger et al. 2006 ) through the production of interleukin $1 \beta$ (Reed et al. 2009). After sustained induction of FGFR1, epithelial cells further proliferated, forming multicellular lesions that eventually became invasive. These invasive lesions were characterized by loss of cell polarity, cell detachment from the basement membrane, and anoikis resistance. Finally, the invasive lesions in iFgfrl transgenic mice were surrounded by an increased number of highly branched small blood vessels (Welm et al. 2002).

The observed changes in the breast epithelium of i F $f r l$ mice were recapitulated in 3D cultures of $\mathrm{HC} 11$ and MCF10A cells transfected with inducible FGFR1 (Welm et al. 2002, Xian et al. 2005, 2009). These models have shown that the induction of $\mathrm{Fgfrl}$ expression results in epithelial to mesenchymal transition.

The molecular downstream targets that are activated upon induction of iFGFR1 include ribosomal protein S6 kinase (RSK (RPS6KA1)), the PI3K-Akt pathway, and the MAPK-ERK pathway (Welm et al. 2002, Xian et al. 2005, 2009). Target genes activated by FGFR1 include several clusters that are linked to tumor formation through angiogenesis, cell cycle regulation, chemotaxis, and the response to inflammation (Schwertfeger et al. 2006).

Activation of FGFR1 does not only affect the characteristics of epithelial cells but also influences the myoepithelium and microenvironment. Long-term activation of FGFR1 in transgenic mice resulted in a disruption of the myoepithelial cell barrier and ECM disorganization (Welm et al. 2002).

Activation of FGFR1 signaling using a small amount of FGF2 in the MDA-MB-134, CAL120, JIMT-1, MFM223, S68, SUM44 (Turner et al. 2010b), CMA, MDA-MB-361, and HCC38 (Shiang et al. 2010) cell lines, which have endogenous FGFRI amplifications, resulted in downstream activation of multiple pathways, including FRS2, ERK1/2 (MAPK3/1), and RSK phosphorylation. A different study showed that these pathways were already basally activated without ligand (Turner et al. 2010b). Also, cells harboring FGFRl amplifications seem to have an oncogenic addiction to FGFR1 signaling as they are highly sensitive to inhibition of FGFR1 by siRNA or SU5402, an FGFR1 TK inhibitor (TKI; Reis-Filho et al. 2006). Furthermore, FGFRI-amplified cell lines were resistant to treatment with 4-hydroxytamoxifen (4-OHT), suggesting that FGFRI amplification is involved in resistance to endocrine therapy (Turner et al. 2010b). This notion supports the observation that amplification of FGFRl is associated with a poor prognosis in ER-positive patients that were treated with tamoxifen as an adjuvant endocrine therapy. Interestingly, inhibition of FGFRl by siRNA increased the sensitivity of FGFR1-amplified cell lines to 4-OHT, making this a possible drug therapy (Turner et al. 2010b). 
Another indication for interacting pathways comes from the mouse mammary tumor virus-wingless type 1 (MMTV-Wnt1) mouse model. Crossing these mice with i Fgfrl transgenic mice and subsequent activation of FGFR1 dramatically accelerated tumor formation, suggesting an interaction between FGFR1 and WNT (WNT) signaling (Pond et al. 2010). Further experiments are needed to explore whether genetic aberrations in FGFRs affect tumor formation in other mouse mammary tumor models harboring mutations in oncogenes that frequently occur in breast cancer patients.

\section{FGFR2}

The FGFR2-amplified SUM52PE and MFM223 cell lines depend on FGFR2 signaling for survival. This addiction to FGFR2 is due to activation of the PI3KAKT signaling pathway that results in inhibition of apoptosis. Furthermore, downstream targets of FGFR signaling like FRS2, AKT, and ERK were phosphorylated in the absence of serum and inactivated by an FGFR inhibitor. This indicates that the phosphorylation of these targets is independent of ligand binding and is dependent on FGFR kinase activity. In contrast, the HCC1143 cell line, in which a mutation in FGFR2 has been described, showed no evidence of FGFRdependent signaling and is not dependent on FGFR for proliferation (Turner et al. 2010a).

As described earlier, SNPs in intron 2 of FGFR2 correlate with higher FGFR2 mRNA expression levels (Meyer et al. 2008). As the sequence of intron 2 includes a regulatory region, SNPs could alter one or more transcription factor binding sites, thereby regulating the expression levels of FGFR2 (Easton et al. 2007). The SNPs rs 35054928 and rs 2981578 are located next to an organic cation transporter (OCT)binding site. The risk allele of rs 2981578 also creates a putative binding site for runt-related transcription factor (RUNX) and the risk allele of rs10736303 one for ER (Katoh \& Katoh 2009). The risk allele of rs7895676 has reduced binding capacity to CCAAT/ enhancer binding protein $\beta$ (C/EBP $\beta$ (CEBPB)). Whereas the rs 2981578 variants have equal affinity for OCT1 (POU2F1), the high-risk allele has much higher affinity for RUNX2 (Meyer et al. 2008), thought to be due to differences in $\mathrm{H} 3 / \mathrm{H} 4$ acetylation of the SNP sites (Zhu et al. 2009). Overall, the differences in binding affinity result in a higher expression of $F G F R 2$ in cell lines carrying the high-risk alleles. This is in accordance with the increased expression levels of FGFR2 in breast cancer samples that were homozygous for the high-risk alleles (Meyer et al.
2008). Remarkably, ER binding was not altered for any of the SNPs, whereas the increased risk for breast cancer due to the high-risk alleles of FGFR2 are highly associated with ER-positive tumors (Garcia-Closas et al. 2008). A possible explanation for this association is that ER and OCT1/RUNX may cooperate to increase the expression of FGFR2 (Meyer et al. 2008), which is supported by the finding that OCT and ER sites often cluster together (Carroll et al. 2006). The exact role of ER in the FGFR2 allele resulting in increased breast cancer risk remains to be investigated.

\section{FGFR3}

MCF7 cells were used to study the molecular mechanisms behind the involvement of FGFR3 in tamoxifen resistance in ER-positive breast cancer. Inducible activation of FGFR3 decreased the sensitivity of MCF7 cells to 4-OHT treatment independent of ER activity. Activation of PLC $\gamma 1$ (PLCG1) was essential for this resistance phenotype and downstream activation of PI3K signaling was an important component of this reduced sensitivity to endocrine therapy (Tomlinson et al. 2012).

\section{FGFR4}

The poor response to chemotherapy associated with overexpression of FGFR4 (Meijer et al. 2008) has been recapitulated in several FGFR4 overexpressing breast cancer cell lines, which are resistant to doxorubicin and cyclophosphamide (Roidl et al. 2009). FGFR4 contributes to this resistance by activating antiapoptotic signaling via activation of MAPK and subsequent increase in the B-cell lymphoma-extra large (BCL-XL) levels. In accordance with this, inhibition of FGFR4 reduced ERK phosphorylation and decreased levels of BCL-XL, ultimately leading to increased chemosensitivity to drugs (Roidl et al. 2009).

The $\mathrm{Arg}^{388}$ SNP in FGFR4 affects its structure, but TK activity was not increased in breast cancer cells expressing this FGFR variant (Bange et al. 2002). This suggests that FGFR4-mediated resistance to chemotherapy may not be due to increased kinase activity of the receptor. Interestingly, Gly ${ }^{388}$-expressing cells are less invasive compared with $\mathrm{Arg}^{388}$-expressing cells or cells that have no endogenous FGFR4 expression (Stadler et al. 2006). This indicates that the $G l y^{388}$ allele protects patients from tumor invasion, which is consistent with a better prognosis (Bange et al. 2002). The kinase domain was proven to be essential for this protective effect (Stadler et al. 2006), suggesting that downstream signaling plays an important role. Gene expression analysis revealed 
upregulation of the lysophosphatidic acid (LPA) receptor gene (EDG2 (LPARI)), matrix metalloproteinase $1(M M P 1)$, and downregulation of plasminogen activator inhibitor (PAIl (SERPINE1)) in $\mathrm{Arg}^{388}$ compared with $G^{3} y^{388}$-expressing cells, possibly contributing to increased cell motility and invasion. EDG2 induces cell migration by activation of PI3 and AKT upon binding of the LPA ligand, which is consistent with increased cell motility in cells expressing $\mathrm{Arg}^{388}$. The observed upregulation of MMP1 in $\operatorname{Arg}^{388}$-expressing cells may contribute to increased invasion due to increased degradation of the ECM (Stadler et al. 2006). PAI1 has been shown to inhibit urokinase plasminogen activator (uPA) resulting in a decrease in migration and invasion. In addition, upregulation of uPA sensitizes the $\mathrm{Arg}^{388}$. expressing cells to chemotherapy-induced apoptosis (Whitley et al. 2004). All these (indirect) downstream targets of the $A r{ }^{388} F G F R 4$ variant seem to increase tumor invasion and decrease sensitivity to chemotherapy, explaining the worse clinical prognosis of $\mathrm{Arg}^{388}$ carriers (Bange et al. 2002, Thussbas et al. 2006).

Decreased invasion and no change in proliferative capacity of $G l y^{388}$-expressing breast cancer cells was also observed in the whey acidic protein-transforming growth factor $\alpha$ (WAP-TGF $\alpha$ ) breast cancer mouse model in which either the $\mathrm{Arg}^{385}$ or $\mathrm{Gly}^{385}$ allele (the mouse equivalents of the human 388 alleles) was knocked in. The tumors of the mice carrying the $\mathrm{Arg}^{385}$ allele were more invasive than in their Gly ${ }^{385}$ littermates due to increased migration (Seitzer et al. 2010).

In addition to increased invasion, WAP-TGF $\alpha$ mice carrying the $\mathrm{Arg}^{385}$ allele also developed highly proliferative lung metastases. Genes suggested to contribute to this effect are cyclin-dependent kinase (CDK) inhibitor 1A (p21), which is downregulated in $\mathrm{Arg}^{385}$ tumor samples and CDK1, FLK1 (KDR; fetal liver kinase-1), CD44, MMP13, and MMP14, which are upregulated in the $\mathrm{Arg}^{385}$ tumors and are involved in cell invasion (Seitzer et al. 2010). Interestingly, the involvement of MMPs in $\mathrm{Arg}^{388}$-mediated tumor progression has also been suggested in breast cancer patients (Sugiyama et al. 2010a,b).

\section{Therapeutic targets and drugs in development}

Based on the genetic aberrations in FGFRs identified in breast cancer patients and their consequences on a molecular level, several approaches can be used to target FGFR signaling.

\section{Upstream intervention}

As described earlier, cell lines with FGFRl amplifications and overexpression have low levels of downstream signaling in the absence of ligand. However, ligand binding strongly induces downstream activation, making inhibition of ligand-receptor interaction a useful approach to inhibit FGFR1 signaling. In FGFR2-amplified cell lines, downstream signaling is ligand independent. Whether the presence of a ligand increases signaling, making ligand interference a useful target, is yet unclear. For patients overexpressing FGFR4, the dependence on ligand binding has yet to be investigated in more detail to determine whether it is useful to target ligand binding.

A possible method to inhibit ligand binding is by designing FGF ligand traps such as FP-1039 (Turner \& Grose 2010): a fusion protein comprising the extracellular domain of FGFR1 and the Fc region of IgG. FP-1039 has been shown to have antiangiogenic effects in vivo. Moreover, FP-1039 was able to block tumor formation of breast cancer cell line xenografts, depending on their expression of FGFs and FGFRs (Zhang et al. 2007). FP-1039 is currently being tested in a phase I clinical trial (Keer 2010). Furthermore, as the FGFRs have several ligands in common, not only FGFR1 activation but also activation of FGFR3 and FGFR4 is blocked by binding of FP-1039 to FGFs (Zhang et al. 2007), making FP-1039 a rather universal blocker of FGFR signaling.

A second method to interfere with ligand binding is the use of antagonistic peptide mimics. These could be effective drugs for patients harboring $F G F R$ amplifications that depend on the presence of a ligand to induce signaling. However, at present, only agonistic peptide mimics have been designed for FGFR1-IIIc and FGFR2IIIb. These were proven to be functional FGFR agonists with apparent therapeutic potential (Li et al. 2008).

\section{Intervention on the FGFR level}

Several methods can be used to target the FGFRs at the receptor level. First of all, numerous TKIs targeting FGFRs have been developed. These small molecules compete with ATP to bind to the receptor resulting in reduced activity of the kinase domain (Katoh \& Katoh 2009, Turner \& Grose 2010). However, as the kinase domains of RTKs are very similar, most TKIs are not specific for one FGFR and also inhibit the activity of VEGFRs and/or PDGFRs (Turner \& Grose 2010). This may in fact increase their activity in cancer patients but perhaps cause more side effects. Brivanib alaninate is an example of a TKI targeting both FGFRs and VEGFRs. Its effect in breast cancer has so far only been 
tested in vitro: cell lines with FGFR1 amplification/ overexpression are more sensitive than nonamplified ones (Marme et al. 2010). The effect of this drug on other FGFRs and in patients remains to be investigated.

Another multitarget drug is dovitinib, an inhibitor of FGFRs, PDGFRs, and VEGFRs. This TKI was tested in a phase II clinical trial (NCT00958971) including HER2-negative breast cancer patients and only showed antitumor activity in patients with an FGFR1 amplification and an ER- and/or PR-positive status, whereas other subgroups only showed stabilization of tumor growth (Andre et al. 2011). Another phase II trial (NCT01262027) with dovitinib has been started to control inflammatory breast cancer and also evaluate the safety of this drug. E-3810 is a multitarget smallmolecule inhibitor targeting VEGFRs and FGFR1, which is currently being tested in a phase I clinical trial. After initial testing in patients with solid tumors, breast cancer patients with FGFRI amplifications are included in the dose expansion phase to obtain preliminary data on the antitumor activity of this drug (clinical trial: NCT01283945). Finally, BIBF1120 was developed as a kinase inhibitor targeting FGFRs, PDGFRs, and VEGFRs. Testing of this drug in multiple cancer mouse models and clinical trials including different cancer types has already been shown to be successful (Hilberg et al. 2008, Antoniu \& Kolb 2010). A phase I/II clinical trial (NCT01484080) is currently investigating its efficacy in combination with paclitaxel (a mitotic inhibitor used to treat several types of cancer) in patients with early HER2-negative breast cancer.

PD173074 and SU5402 are the first compounds that have been designed as FGFR-specific TKIs. PD173074 was effective in ER-, PR-, and HER2-negative cell lines with FGFR2 amplification/overexpression (Turner et al. 2010a). SU5402 decreased proliferation exclusively in cell lines with FGFRI amplification and overexpression (Reis-Filho et al. 2006). It must be noted, however, that not every cell line with FGFR1 amplifications is sensitive to FGFR1 inhibition, which was found to depend on the oncogenic background (Reis-Filho et al. 2006). In this regard, further in vitro and in vivo studies will have to be performed in order to identify the right subgroup among patients with FGFRl amplification and overexpression who will respond to FGFR-specific drugs.

The efficacy and safety of AZD4547, a TKI that targets FGFRs, are currently being tested in a phase IIa clinical trial (NCT01202591). The patients included are ER positive and have FGFRl polysomy or gene amplification and are also treated with exemestane, an aromatase inhibitor used to treat ER-positive breast cancer (Lintermans et al. 2011). Another pan-FGFR inhibitor (BGJ398) is also currently being tested in a phase 1 clinical trial to determine the maximum tolerated dose (clinical trial NCT01004224). This trial includes patients with solid tumors with FGFRI or -2 amplifications or FGFR3 mutations.

Monoclonal antibodies may be a good solution to circumvent the side effects of unspecific TKIs. There are FGFR1-IIIc- and FGFR3-specific antibodies that have not yet been tested in any breast cancer model (Turner \& Grose 2010). An anti-FGFR4 antibody (10F10) strongly increased sensitivity to doxorubicin in cell lines naturally overexpressing FGFR4 (Roidl et al. 2009).

Another potentially highly specific way to target FGFRs is by RNA aptamers. These short RNA oligonucleotides are selected for their high affinity and specificity for their target protein, thereby acting as synthetic antibodies (Ireson \& Kelland 2006). Currently, RNA aptamers that target the FGFR2 kinase domain, the $F R S 2$ interacting domain, and the extracellular domain of FGFR2 are being developed, but their effectiveness remains to be tested (Katoh \& Katoh 2009). Therapeutic strategies using siRNA or miRNA are still in a very early stage of development focusing on off-target effects and delivery (Katoh \& Katoh 2009).

\section{Downstream intervention}

Many of the proteins involved in FGFR signaling also play a role in other signaling pathways and in healthy cells. This makes it very difficult to target these proteins without side effects. No extensive research has been performed on targeting the downstream effectors of FGFR signaling. The targets suggested below are therefore mostly hypothetical, whereas for some, preliminary data are present.

In FGFR1-transfected MCF10A cells, treatment with chloromethylketone (CMK), an irreversible small molecule inhibitor specific for RSK (Cohen et al. 2005), reduced proliferation and restored sensitivity to anoikis (Xian et al. 2009). Interestingly, the inhibitory effect of CMK was only observed in breast cancer cell lines overexpressing FGFR1 (Xian et al. 2009). The effect of CMK in vivo remains to be investigated.

MMPs could also be possible drug targets downstream of FGFR1. Inhibition of MMPs in HC11 cells overexpressing FGFRl with a pan-MMP inhibitor (GM6001) resulted in decreased invasion and epithelial mesenchymal transition (EMT), although proliferation, apoptosis, and cell polarity were not changed (Xian et al. 2005). This indicates that inhibition of MMP activity may not suffice as mono 
treatment but could be useful when used in combination with other drugs.

PI3 kinase is a possible drug target for patients with $F G F R 2$ amplifications, as FGFR2-amplified cell lines are dependent on PI3K-mediated inhibition apoptosis for their survival. This idea is supported by a study in FGFR2-amplified cell lines, which found that dual targeting of FGFR2 and PI3 kinase by PD173074 and BEZ235 (a PI3 kinase/mTOR inhibitor), respectively, was very effective (Adelaide et al. 2007). As PI3K signaling is also suggested to be important in FGFR3mediated resistance to tamoxifen, the inhibition of this pathway could also be a potential treatment for this group of patients.

In patients with FGFR4 overexpression, targeting the antiapoptotic pathway that activates BCL-XL via MAPK might be a possibility. As these proteins have been shown to mediate chemotherapy resistance in this group of patients, drugs targeting them could increase the response rate. No clinical studies in this field have been performed so far, but administration of UO126 (a specific MEK inhibitor) to FGFR4-expressing breast cancer cells has been shown to decrease BCL-XL expression (Roidl et al. 2009). In addition to a broad panel of MEK inhibitors that have been developed to treat different types of cancer (Fremin \& Meloche 2010), BCL-XL inhibitors are also available for clinical research (Kang \& Reynolds 2009).

As the FGFR4-Arg ${ }^{388}$ polymorphism does not result in increased TK activity (Bange et al. 2002), drugs interfering with ligand binding or the TK activity of the receptor are unsuitable for treating FGFR4-Arg ${ }^{388}$ breast cancer patients. However, as described earlier, numerous downstream effectors of FGFR4 play a role in the increased migration capacity of $\mathrm{Arg}^{388}$-expressing cells. Interference with any of these molecules could be a potential therapeutic strategy for breast cancer patients harboring the $\operatorname{Arg}^{388}$ allele. This is supported by the observation that siRNA targeting EDG2 significantly reduces the migration of cells carrying the $\mathrm{Arg}^{388} \mathrm{FGFR} 4$ allele (Stadler et al. 2006).

In general, when targeting FGFR signaling, its role in proliferation, differentiation, migration, and angiogenesis should be kept in mind. Interfering in these important basic cell processes could have many side effects. Further investigation of the context-dependent activation of downstream pathways is necessary to anticipate these side effects.

\section{Conclusion}

In the past decade, our understanding of the important role of FGFRs in breast cancer has been growing.
Genetic aberrationsTcharrsid10362901 in different FGFRs have been identified in subgroups of breast cancer patients, and their (molecular) implications on tumor characteristics have been partly elucidated. Overall, it is very clear that FGFRs are promising drug targets. FGFR2 amplifications could be a very interesting drug target in triple-negative breast cancer patients, as other targeted therapies are not effective. Although several mutations in FGFR3 have been found in other types of cancer and its overexpression has been associated with endocrine resistance, genetic aberrations affecting FGFR3 have not been identified in breast cancer patients (Sibley et al. 2001). Future experiments should be focused on the molecular mechanism behind the increased breast cancer risk associated with the SNPs in intron 2 of FGFR2, especially addressing the role of ER. Some contradicting results regarding the involvement of the Arg ${ }^{388}$ FGFR4 allele in the prognosis and therapy resistance of breast cancer patients should be clarified by large-scale studies in which the clinical and pathological parameters are monitored closely. Furthermore, the FGFRI gene amplification observed that several different types of breast cancer make it a very relevant drug target. As the inducible FGFR1 models have greatly increased the understanding about its molecular mechanism, the next step should be to screen for possible drugs. Interestingly, in contrast to $F G F R 1$, expression of FGFR2 did not induce neoplasia in the prostate (Freeman et al. 2003), suggesting that FGFR1 is more oncogenic than FGFR2. However, whether this is also the case in mammary tissue or this oncogenic potency is an issue of context remains to be investigated.

Several FGFR-targeting strategies are in different phases of development. In addition to the drugs described earlier, several other compounds targeting FGFRs are being tested on other types of cancer, including urothelial carcinoma, non-small-cell lung cancer, and ovarian cancer (Katoh \& Katoh 2009, Antoniu \& Kolb 2010, Turner \& Grose 2010, Bello et al. 2011, Lamont et al. 2011). Even though most of these drugs are not specific for FGFRs, but also target PDGFRs and VEGFRs, this might actually be an advantage as these RTKs are known for their roles in tumor angiogenesis and proliferation (Petrelli \& Giordano 2008). Likely, further refinements in FGFR-targeting drugs will be necessary to increase effectiveness and limit side effects. At the same time, translational studies need to identify the subgroup of breast cancer patients that will best respond to the various FGFR-targeted therapies. 


\section{Declaration of interest}

The authors declare that there is no conflict of interest that could be perceived as prejudicing the impartiality of the review reported.

\section{Funding}

Supported by unrestricted educational grants from Aegon, Inc. and Pink Ribbon, The Netherlands.

\section{References}

Acevedo VD, Ittmann M \& Spencer DM 2009 Paths of FGFR-driven tumorigenesis. Cell Cycle 8 580-588. (doi:10.4161/cc.8.4.7657)

Adelaide J, Finetti P, Bekhouche I, Repellini L, Geneix J, Sircoulomb F, Charafe-Jauffret E, Cervera N, Desplans J, Parzy D et al. 2007 Integrated profiling of basal and luminal breast cancers. Cancer Research 67 11565-11575. (doi:10.1158/0008-5472.CAN-07-2536)

Alvarez RH, Valero V \& Hortobagyi GN 2010 Emerging targeted therapies for breast cancer. Journal of Clinical Oncology 28 3366-3379. (doi:10.1200/JCO.2009.25. 4011)

Andre F, Job B, Dessen P, Tordai A, Michiels S, Liedtke C, Richon C, Yan K, Wang B, Vassal G et al. 2009 Molecular characterization of breast cancer with highresolution oligonucleotide comparative genomic hybridization array. Clinical Cancer Research 15 441-451. (doi:10.1158/1078-0432.CCR-08-1791)

Andre F, Bachelot D, Campone M, Dalenc F, Perez-Garcia JM, Hurvitz SA, Turner NC, Rugo HS, Shi MM, Zhang Y et al. 2011 A multicenter, open-label phase II trial of dovitinib, an FGFR1 inhibitor, in FGFR1 amplified and non-amplified metastatic breast cancer. Journal of Clinical Oncology 29 S508. (doi:10.1200/JCO.2010.31.6877)

Antoniu SA \& Kolb MR 2010 Intedanib, a triple kinase inhibitor of VEGFR, FGFR and PDGFR for the treatment of cancer and idiopathic pulmonary fibrosis. IDrugs: the Investigational Drugs Journal 13 332-345.

Arteaga CL 2003 Inhibiting tyrosine kinases: successes and limitations. Cancer Biology \& Therapy 2 S79-S83.

Bane AL, Pinnaduwage D, Colby S, Bull SB, O’Malley FP \& Andrulis IL 2009 Expression profiling of familial breast cancers demonstrates higher expression of FGFR2 in BRCA2-associated tumors. Breast Cancer Research and Treatment 117 183-191. (doi:10.1007/s10549-008-0087-1)

Bange J, Prechtl D, Cheburkin Y, Specht K, Harbeck N, Schmitt M, Knyazeva T, Muller S, Gartner S, Sures I et al. 2002 Cancer progression and tumor cell motility are associated with the FGFR4 $\operatorname{Arg}(388)$ allele. Cancer Research 62 840-847.

Beenken A \& Mohammadi M 2009 The FGF family: biology, pathophysiology and therapy. Nature Reviews. Drug Discovery 8 235-253. (doi:10.1038/nrd2792)

Bello E, Colella G, Scarlato V, Oliva P, Berndt A, Valbusa G, Serra SC, D'Incalci M, Cavalletti E, Giavazzi R et al.
2011 E-3810 is a potent dual inhibitor of VEGFR and FGFR that exerts antitumor activity in multiple preclinical models. Cancer Research 71 1396-1405. (doi:10.1158/ 0008-5472.CAN-10-2700)

Bernard-Pierrot I, Gruel N, Stransky N, Vincent-Salomon A, Reyal F, Raynal V, Vallot C, Pierron G, Radvanyi F \& Delattre O 2008 Characterization of the recurrent 8p11-12 amplicon identifies PPAPDC1B, a phosphatase protein, as a new therapeutic target in breast cancer. Cancer Research 68 7165-7175. (doi:10.1158/0008-5472.CAN-08-1360)

Bild AH, Yao G, Chang JT, Wang Q, Potti A, Chasse D, Joshi MB, Harpole D, Lancaster JM, Berchuck A et al. 2006 Oncogenic pathway signatures in human cancers as a guide to targeted therapies. Nature 439 353-357. (doi:10.1038/nature04296)

Cappellen D, De Oliveira C, Ricol D, de Medina S, Bourdin J, Sastre-Garau X, Chopin D, Thiery JP \& Radvanyi F 1999 Frequent activating mutations of FGFR3 in human bladder and cervix carcinomas. Nature Genetics 23 18-20. (doi:10.1038/12615)

Carroll JS, Meyer CA, Song J, Li W, Geistlinger TR, Eeckhoute J, Brodsky AS, Keeton EK, Fertuck KC, Hall G et al. 2006 Genome-wide analysis of estrogen receptor binding sites. Nature Genetics 38 1289-1297. (doi:10.1038/ng1901)

Chin K, De Vries S, Fridlyand J, Spellman PT, Roydasgupta R, Kuo WL, Lapuk A, Neve RM, Qian Z, Ryder T et al. 2006 Genomic and transcriptional aberrations linked to breast cancer pathophysiologies. Cancer Cell 10 529-541. (doi:10.1016/j.ccr.2006.10.009)

Cohen MS, Zhang C, Shokat KM \& Taunton J 2005 Structural bioinformatics-based design of selective, irreversible kinase inhibitors. Science 308 1318-1321. (doi:10.1126/science1108367)

Dailey L, Ambrosetti D, Mansukhani A \& Basilico C 2005 Mechanisms underlying differential responses to FGF signaling. Cytokine \& Growth Factor Reviews 16 233-247. (doi:10.1016/j.cytogfr.2005.01.007)

Easton DF, Pooley KA, Dunning AM, Pharoah PD, Thompson D, Ballinger DG, Struewing JP, Morrison J, Field H, Luben R et al. 2007 Genome-wide association study identifies novel breast cancer susceptibility loci. Nature 447 1087-1093. (doi:10.1038/nature05887)

Elbauomy Elsheikh S, Green AR, Lambros MB, Turner NC, Grainge MJ, Powe D, Ellis IO \& Reis-Filho JS 2007 FGFR1 amplification in breast carcinomas: a chromogenic in situ hybridisation analysis. Breast Cancer Research 9 R23. (doi:10.1186/bcr1665)

Eswarakumar VP, Lax I \& Schlessinger J 2005 Cellular signaling by fibroblast growth factor receptors. Cytokine \& Growth Factor Reviews 16 139-149. (doi:10.1016/j. cytogfr.2005.01.001)

Ferlay J, Shin HR, Bray F, Forman D, Mathers C \& Parkin DM 2008 Globocan 2008 v1.2, Cancer incidence and mortality worldwide: IARC CancerBase No. 10. Available from: http://globocan.iarc.fr accessed on 20/10/2010. 
Freeman KW, Welm BE, Gangula RD, Rosen JM, Ittmann M, Greenberg NM \& Spencer DM 2003 Inducible prostate intraepithelial neoplasia with reversible hyperplasia in conditional FGFR1-expressing mice. Cancer Research 63 8256-8263.

Fremin C \& Meloche S 2010 From basic research to clinical development of MEK1/2 inhibitors for cancer therapy. Journal of Hematology \& Oncology 3 8. (doi:10.1186/ 1756-8722-3-8)

Garcia MJ, Pole JC, Chin SF, Teschendorff A, Naderi A, Ozdag H, Vias M, Kranjac T, Subkhankulova T, Paish C et al. $2005 \mathrm{~A} 1 \mathrm{Mb}$ minimal amplicon at 8p11-12 in breast cancer identifies new candidate oncogenes. Oncogene $\mathbf{2 4}$ 5235-5245. (doi:10.1038/sj.onc.1208741)

Garcia-Closas M, Hall P, Nevanlinna H, Pooley K, Morrison J, Richesson DA, Bojesen SE, Nordestgaard BG, Axelsson CK, Arias JI et al. 2008 Heterogeneity of breast cancer associations with five susceptibility loci by clinical and pathological characteristics. PLoS Genetics 4 e1000054. (doi:10.1371/journal.pgen.1000054)

Gelsi-Boyer V, Orsetti B, Cervera N, Finetti P, Sircoulomb F, Rougé C, Lasorsa L, Letessier A, Ginestier C, Monville F et al. 2005 Comprehensive profiling of 8p11-12 amplification in breast cancer. Molecular Cancer Research 3 655-667. (doi:10.1158/1541-7786.MCR-05-0128)

Greenman C, Stephens P, Smith R, Dalgliesh GL, Hunter C, Bignell G, Davies H, Teague J, Butler A, Stevens C et al. 2007 Patterns of somatic mutation in human cancer genomes. Nature 446 153-158. (doi:10.1038/nature05610)

Hafner C, Vogt T \& Hartmann A 2006 FGFR3 mutations in benign skin tumors. Cell Cycle 5 2723-2728. (doi:10.4161/cc.5.23.3509)

Harmer NJ, Ilag LL, Mulloy B, Pellegrini L, Robinson CV \& Blundell TL 2004 Towards a resolution of the stoichiometry of the fibroblast growth factor (FGF)-FGF receptor-heparin complex. Journal of Molecular Biology 339 821-834. (doi:10.1016/j.jmb.2004.04.031)

Hilberg F, Roth GJ, Krssak M, Kautschitsch S, Sommergruber W, Tontsch-Grunt U, Garin-Chesa P, Bader G, Zoephel A, Quant J et al. 2008 BIF1120: a tripple angiokinase inhibitor with sustained receptor bockade and good antitumor efficacy. Cancer Research 68 4774-4782. (doi:10.1158/0008-5472.CAN-07-6307)

Hunter DJ, Kraft P, Jacobs KB, Cox DG, Yeager M, Hankinson SE, Wacholder S, Wang Z, Welch R, Hutchinson A et al. 2007 A genome-wide association study identifies alleles in FGFR2 associated with risk of sporadic postmenopausal breast cancer. Nature Genetics 39 870-874. (doi:10.1038/ng2075)

Ireson CR \& Kelland LR 2006 Discovery and development of anticancer aptamers. Molecular Cancer Therapeutics 5 2957-2962. (doi:10.1158/1535-7163.MCT-06-0172)

Jaakkola S, Salmikangas P, Nylund S, Partanen J, Armstrong E, Pyrhonen S, Lehtovirta P \& Nevanlinna H 1993

Amplification of fgfr4 gene in human breast and gynecological cancers. International Journal of Cancer $\mathbf{5 4}$ 378-382. (doi:10.1002/ijc.2910540305)
Jemal A, Center MM, DeSantis C \& Ward EM 2010

Global patterns of cancer incidence and mortality rates and trends. Cancer Epidemiology, Biomarkers \& Prevention 19 1893-1907. (doi:10.1158/1055-9965. EPI-10-0437)

Jezequel P, Campion L, Joalland MP, Millour M, Dravet F, Classe JM, Delecroix V, Deporte R, Fumoleau P \& Ricolleau G 2004 G388R mutation of the FGFR4 gene is not relevant to breast cancer prognosis. British Journal of Cancer 90 189-193. (doi:10.1038/sj.bjc.6601450)

Kadota M, Sato M, Duncan B, Ooshima A, Yang HH, Diaz-Meyer N, Gere S, Kageyama S, Fukuoka J, Nagata T et al. 2009 Identification of novel gene amplifications in breast cancer and coexistence of gene amplification with an activating mutation of PIK3CA. Cancer Research 69 7357-7365. (doi:10.1158/0008-5472.CAN-09-0064)

Kan Z, Jaiswal BS, Stinson J, Janakiraman V, Bhatt D, Stern HM, Yue P, Haverty PM, Bourgon R, Zheng J et al. 2010 Diverse somatic mutation patterns and pathway alterations in human cancers. Nature 466 869-873. (doi:10.1038/nature09208)

Kang MH \& Reynolds CP 2009 Bcl-2 inhibitors: targeting mitochondrial apoptotic pathways in cancer therapy. Clinical Cancer Research 15 1126-1132. (doi:10.1158/ 1078-0432.CCR-08-0144)

Katoh Y \& Katoh M 2009 FGFR2-related pathogenesis and FGFR2-targeted therapeutics (review). International Journal of Molecular Medicine 23 307-311.

Keer H 2010 Safety study of FP1039 to treat cancer, Five Prime Therapeutics Inc and Parexel, Clinicaltrials.gov identifier: NCT00687505.

Koziczak M, Holbro T \& Hynes NE 2004 Blocking of FGFR signaling inhibits breast cancer cell proliferation through downregulation of D-type cyclins. Oncogene $\mathbf{2 3}$ 3501-3508. (doi:10.1038/sj.onc.1207331)

Kurosu H, Ogawa Y, Miyoshi M, Yamamoto M, Nandi A, Rosenblatt KP, Baum MG, Schiavi S, Hu MC, Moe OW et al. 2006 Regulation of fibroblast growth factor-23 signaling by klotho. Journal of Biological Chemistry 281 6120-6123. (doi:10.1074/jbc.C500457200)

Lamont FR, Tomlinson DC, Cooper PA, Shnyder SD, Chester JD \& Knowles MA 2011 Small molecule FGF receptor inhibitors block FGFR-dependent urothelial carcinoma growth in vitro and in vivo. British Journal of Cancer 104 75-82. (doi:10.1038/sj.bjc.6606016)

Letessier A, Sircoulomb F, Ginestier C, Cervera N, Monville F, Gelsi-Boyer V, Esterni B, Geneix J, Finetti P, Zemmour C et al. 2006 Frequency, prognostic impact, and subtype association of $8 \mathrm{p} 12,8 \mathrm{q} 24,11 \mathrm{q} 13,12 \mathrm{p} 13,17 \mathrm{q} 12$, and $20 \mathrm{q} 13$ amplifications in breast cancers. BMC Cancer 6245. (doi:10.1186/1471-2407-6-245)

Li S, Christensen C, Kiselyov VV, Kohler LB, Bock E \& Berezin V 2008 Fibroblast growth factor-derived peptides: functional agonists of the fibroblast growth factor receptor. Journal of Neurochemistry 104 667-682. (doi:10.1111/j.1471-4159.2007.05070.x) 
Lintermans A, Neven P \& Paridaens R 2011 Drug safety evaluation of exemestane. Expert Opinion on Drug Safety 10 473-487. (doi:10.1517/14740338.2011.567264)

Marchio C, Iravani M, Natrajan R, Lambros MB, Savage K, Tamber N, Fenwick K, Mackay A, Senetta R, Di Palma S et al. 2008 Genomic and immunophenotypical characterization of pure micropapillary carcinomas of the breast. Journal of Pathology 215 398-410. (doi:10.1002/path.2368)

Marme F, Werft W, Benner A, Burwinkel B, Sinn P, Sohn C, Lichter P, Hahn M \& Schneeweiss A 2010 FGFR4 Arg388 genotype is associated with pathological complete response to neoadjuvant chemotherapy for primary breast cancer. Annals of Oncology 21 1636-1642. (doi:10.1093/annonc/mdq017)

Meijer D, Sieuwerts AM, Look MP, van Agthoven T, Foekens JA \& Dorssers LC 2008 Fibroblast growth factor receptor 4 predicts failure on tamoxifen therapy in patients with recurrent breast cancer. Endocrine-Related Cancer 15 101-111. (doi:10.1677/ERC-07-0080)

Meyer KB, Maia AT, O'Reilly M, Teschendorff AE, Chin SF, Caldas C \& Ponder BA 2008 Allele-specific up-regulation of FGFR2 increases susceptibility to breast cancer. PLoS Biology 6 e108. (doi:10.1371/journal.pbio.0060108)

Moelans CB, de Weger RA, Monsuur HN, Vijzelaar R \& van Diest PJ 2010 Molecular profiling of invasive breast cancer by multiplex ligation-dependent probe amplification-based copy number analysis of tumor suppressor and oncogenes. Modern Pathology 23 1029-1039. (doi:10.1038/modpathol.2010.84)

Mohammadi M, Olsen SK \& Ibrahimi OA 2005 Structural basis for fibroblast growth factor receptor activation. Cytokine \& Growth Factor Reviews 16 107-137. (doi:10.1016/j.cytogfr.2005.01.008)

Mukai H 2010 Targeted therapy in breast cancer: current status and future directions. Japanese Journal of Clinical Oncology 40 711-716. (doi:10.1093/jjco/hyq037)

Penault-Llorca F, Bertucci F, Adelaide J, Parc P, Coulier F, Jacquemier J, Birnbaum D \& deLapeyriere O 1995 Expression of FGF and FGF receptor genes in human breast cancer. International Journal of Cancer $\mathbf{6 1}$ 170-176. (doi:10.1002/ijc.2910610205)

Peterson C 2011 Drug therapy of cancer. European Journal of Clinical Pharmacology 67 437-447. (doi:10.1007/s00228-011-1011-x)

Petrelli A \& Giordano S 2008 From single- to multi-target drugs in cancer therapy: when aspecificity becomes an advantage. Current Medicinal Chemistry 15 422-432. (doi:10.2174/092986708783503212)

Pond AC, Herschkowitz JI, Schwertfeger KL, Welm B, Zhang Y, York B, Cardiff RD, Hilsenbeck S, Perou CM, Creighton CJ et al. 2010 Fibroblast growth factor receptor signaling dramatically accelerates tumorigenesis and enhances oncoprotein translation in the mouse mammary tumor virusWnt-1 mouse model of breast cancer. Cancer Research 70 4868-4879. (doi:10.1158/0008-5472.CAN-09-4404)

Prosnitz LR, Iglehart JD \& Winer EP 2001 Chapter 17: breast cancer. In Clinical Oncology: A Multi-disciplinary
Approach for Physicians and Students, 8th edn, pp 267-273. Eds P Rubin \& JP Williams. Waltham, MA, USA: Elsevier health sciences.

Ray ME, Yang ZQ, Albertson D, Kleer CG, Washburn JG, Macoska JA \& Ethier SP 2004 Genomic and expression analysis of the 8p11-12 amplicon in human breast cancer cell lines. Cancer Research 64 40-47. (doi:10.1158/00085472.CAN-03-1022)

Reed JR, Leon RP, Hall MK \& Schwertfeger KL 2009 Interleukin-1beta and fibroblast growth factor receptor 1 cooperate to induce cyclooxygenase- 2 during early mammary tumourigenesis. Breast Cancer Research 11 R21. (doi:10.1186/bcr2246)

Reis-Filho JS, Simpson PT, Turner NC, Lambros MB, Jones C, Mackay A, Grigoriadis A, Sarrio D, Savage K, Dexter T et al. 2006 FGFR1 emerges as a potential therapeutic target for lobular breast carcinomas. Clinical Cancer Research 12 6652-6662. (doi:10.1158/10780432.CCR-06-1164)

Roidl A, Berger HJ, Kumar S, Bange J, Knyazev P \& Ullrich A 2009 Resistance to chemotherapy is associated with fibroblast growth factor receptor 4 up-regulation. Clinical Cancer Research 15 2058-2066. (doi:10.1158/ 1078-0432.CCR-08-0890)

Sahlin P, Tarnow P, Martinsson T \& Stenman G 2009 Germline mutation in the FGFR3 gene in a TWIST1negative family with Saethre-Chotzen syndrome and breast cancer. Genes, Chromosomes \& Cancer 48 285-288. (doi:10.1002/gcc.20637)

Schwertfeger KL, Xian W, Kaplan AM, Burnett SH, Cohen DA \& Rosen JM 2006 A critical role for the inflammatory response in a mouse model of preneoplastic progression. Cancer Research 66 5676-5685. (doi:10.1158/0008-5472.CAN-05-3781)

Seitzer N, Mayr T, Streit S \& Ullrich A 2010 A single nucleotide change in the mouse genome accelerates breast cancer progression. Cancer Research 70 802-812. (doi:10.1158/0008-5472. CAN-09-3239)

Shiang CY, Qi Y, Wang B, Lazar V, Wang J, Fraser Symmans W, Hortobagyi GN, Andre F \& Pusztai L 2010 Amplification of fibroblast growth factor receptor-1 in breast cancer and the effects of brivanib alaninate. Breast Cancer Research and Treatment 123 747-755. (doi:10.1007/s10549-009-0677-6)

Sibley K, Stern P \& Knowles MA 2001 Frequency of fibroblast growth factor receptor 3 mutations in sporadic tumours. Oncogene 20 4416-4418. (doi:10.1038/sj.onc. 1204543)

Sjöblom T, Jones S, Wood LD, Parsons DW, Lin J, Barber TD, Mandelker D, Leary RJ, Ptak J, Silliman N et al. 2006 The consensus coding sequence of human breast and colorectal cancers. Science 314 268-274. (doi:10.1126/science.1133427)

Stadler CR, Knyazev P, Bange J \& Ullrich A 2006 FGFR4 GLY388 isotype suppresses motility of 
MDA-MB-231 breast cancer cells by EDG-2 gene repression. Cellular Signalling 18 783-794. (doi:10.1016/j.cellsig.2005.07.002)

Stephens P, Edkins S, Davies H, Greenman C, Cox C, Hunter C, Bignell G, Teague J, Smith R, Stevens C et al. 2005 A screen of the complete protein kinase gene family identifies diverse patterns of somatic muations in human breast cancer. Nature Genetics 37 590-592. (doi:10.1038/ng1571)

Sugiyama N, Varjosalo M, Meller P, Lohi J, Chan KM, Zhou Z, Alitalo K, Taipale J, Keski-Oja J, Lehti K et al. 2010 a FGF receptor-4 (FGFR4) polymorphism acts as an activity switch of a membrane type 1 matrix metalloproteinase-FGFR4 complex. PNAS 107 15786-15791. (doi:10.1073/pnas.0914459107)

Sugiyama N, Varjosalo M, Meller P, Lohi J, Hyytiainen M, Kilpinen S, Kallioniemi O, Ingvarsen S, Engelholm LH, Taipale J et al. 2010b Fibroblast growth factor receptor 4 regulates tumor invasion by coupling fibroblast growth factor signaling to extracellular matrix degradation. Cancer Research 80 7851-7861. (doi:10.1158/00085472.CAN-10-1223)

Sun S, Jiang Y, Zhang G, Song H, Zhang X, Zhang Y, Liang X, Sun Q \& Pang D 2011 Increased expression of fibroblastic growth factor receptor 2 is correlated with poor prognosis in patients with breast cancer. Journal of Surgical Oncology 105 773-779. (doi:10.1002/jso. 22120)

Tomlinson D, Knowles M \& Speirs V 2012 Mechanisms of FGFR3 actions in endocrine resistant breast cancer. International Journal of Cancer 130 2857-2866. (doi:10.1002/ijc.26304)

Thussbas C, Nahrig J, Streit S, Bange J, Kriner M, Kates R, Ulm K, Kiechle M, Hoefler H, Ullrich A et al. 2006 FGFR4 Arg388 allele is associated with resistance to adjuvant therapy in primary breast cancer. Journal of Clinical Oncology 24 3747-3755. (doi:10.1200/JCO. 2005.04.8587)

Turner N \& Grose R 2010 Fibroblast growth factor signalling: from development to cancer. Nature Reviews. Cancer 10 116-129. (doi:10.1038/nrc2780)

Turner N, Lambros MB, Horlings HM, Pearson A, Sharpe R, Natrajan R, Geyer FC, van Kouwenhove M, Kreike B, Mackay A et al. 2010a Integrative molecular profiling of triple negative breast cancers identifies amplicon drivers and potential therapeutic targets. Oncogene 29 2013-2023. (doi:10.1038/onc.2009.489)

Turner N, Pearson A, Sharpe R, Lambros M, Geyer F, Lopez-Garcia MA, Natrajan R, Marchio C, Iorns E, Mackay A et al. 2010b FGFR1 amplification drives endocrine therapy resistance and is a therapeutic target in breast cancer. Cancer Research 70 2085-2094. (doi:10.1158/0008-5472.CAN-09-3746)

Vainikka S, Joukov V, Wennstrom S, Bergman M, Pelicci PG \& Alitalo K 1994 Signal transduction by fibroblast growth factor receptor-4 (FGFR-4). Comparison with FGFR-1. Journal of Biological Chemistry 269 18320-18326.
Welm BE, Freeman KW, Chen M, Contreras A, Spencer DM \& Rosen JM 2002 Inducible dimerization of FGFR1: development of a mouse model to analyze progressive transformation of the mammary gland. Journal of Cell Biology 157 703-714. (doi:10.1083/jcb.200107119)

Whitley BR, Palmieri D, Twerdi CD \& Church FC 2004 Expression of active plasminogen activator inhibitor-1 reduces cell migration and invasion in breast and gynecological cancer cells. Experimental Cell Research 296 151-162. (doi:10.1016/j.yexcr.2004.02.022)

Wu DQ, Kan MK, Sato GH, Okamoto T \& Sato JD 1991 Characterization and molecular cloning of a putative binding protein for heparin-binding growth factors. Journal of Biological Chemistry 266 16778-16785.

Xian W, Schwertfeger KL, Vargo-Gogola T \& Rosen JM 2005 Pleiotropic effects of FGFR1 on cell proliferation, survival, and migration in a 3D mammary epithelial cell model. Journal of Cell Biology 171 663-673. (doi:10.1083/jcb.200505098)

Xian W, Schwertfeger KL \& Rosen JM 2007 Distinct roles of fibroblast growth factor receptor 1 and 2 in regulating cell survival and epithelial-mesenchymal transition. Molecular Endocrinology 21 987-1000. (doi:10.1210/me. 2006-0518)

Xian W, Pappas L, Pandya D, Selfors LM, Derksen PW, de Bruin M, Gray NS, Jonkers J, Rosen JM \& Brugge JS 2009 Fibroblast growth factor receptor 1-transformed mammary epithelial cells are dependent on RSK activity for growth and survival. Cancer Research $692244-2251$. (doi:10.1158/0008-5472.CAN-08-3398)

Yang ZQ, Streicher KL, Ray ME, Abrams J \& Ethier SP 2006 Multiple interacting oncogenes on the 8p11-12 amplicon in human breast cancer. Cancer Research 66 11632-11643. (doi:10.1158/0008-5472.CAN-06-2946)

Zhang Y, Hiraishi Y, Wang H, Sumi KS, Hayashido Y, Toratani S, Kan M, Sato JD \& Okamoto T 2005 Constitutive activating mutation of the FGFR3b in oral squamous cell carcinomas. International Journal of Cancer 117 166-168. (doi:10.1002/ijc.21145)

Zhang H, Masuoka LB, Sadra AB, Brennan T, Doberstein S, Goodworth G, Hestir K, Hollenbaugh D, Long L, Qin M, et al. 2007 LT FP-1039 (FGFR1:Fc), A soluble FGFR1 receptor antagonist, inhibits tumor growth and angiogenesis. AACR-NCI-ERTC International Conference, San Francisco.

Zhu X, Asa SL \& Ezzat S 2009 Histone-acetylated control of fibroblast growth factor receptor 2 intron 2 polymorphisms and isoform splicing in breast cancer. Molecular Endocrinology 23 1397-1405. (doi:10.1210/ me.2009-0071)

Received in final form 11 April 2012

Accepted 16 April 2012

Made available online as an Accepted Preprint 16 April 2012 